\section{Los Montes Orientales de Granada servirán de ensayo general para las cartas patrimoniales de Andalucía}

La Dirección General de Bienes Culturales de la Consejería de Cultura de la Junta de Andalucía ha emprendido una serie de medidas para aumentar el nivel de protección de los bienes culturales. Entre ellas está la puesta en marcha de la primera Carta del Patrimonio Cultural, en este caso de la comarca de los Montes Orientales de Granada, con el fin de crear un instrumento de gestión que ayude a evaluar los bienes culturales existentes en la zona. La Carta Patrimonial sigue la senda de otras medidas impulsadas por la Consejería, como las Cartas Arqueológicas y Etnológicas.

Las Cartas del Patrimonio Cultural en Andalucia, conocidas también como Patrimoniales, son instrumentos técnicos de evaluación y diagnóstico de todos los bienes de la cultura, materiales e inmateriales, que revelen interés histórico, arqueológico, etnológico, artístico, científico o industrial, incluidas sus particularidades lingüisticas.

Desde el pasado año, la Dirección General de Bienes Culturales viene apostando por este instrumento de gestión y tutela que abarca la totalidad del patrimonio cultural de un ámbito determinado con el fin, no sólo de aplicar nuevas formas de protección y conservación, sino de ser tenido en cuenta en las líneas estratégicas de desarrollo, la cohesión social y de ordenación del territorio de nuestra Comunidad.

De esta manera, dentro de las tradicionales lineas de fomento de la Consejeria, tendrá lugar la puesta en marcha en los próximos dias de la primera Carta Patrimonial en Andalucia, cuyo lugar de ensayo será una unidad geográfica bien diferenciada, con predominio de la montaña media y que ocupa $1.400 \mathrm{~km}$ cuadrados. Hablamos, sin duda, de la Comarca de Montes Orientales de Granada, compuesta por 17 municipios y con más de 30.000 habitantes. En ella se conjuga un rico y variado patrimonio cultural tangible (arqueológico, histórico, artístico, antropológico, paleontológico, artesanal,...)
Paisaje en Torre Cardela (Granada). Foto: Elena Ramírez Fernández

\section{Las cartas patrimoniales} diagnostican, establecen directrices para el tratamiento preventivo y proponen actuaciones que permitan proteger, conservar, investigar y poner el patrimonio a disposición de la ciudadanía

e intangible (tradiciones, rituales festivos, oficios, saberes y modos de hacer, alimentación y cocinas, memoria social,...).

Con dicha Carta, se pretende conseguir un instrumento de gestión que sea útil, tanto a las administraciones municipales como a la autonómica para reducir el número de situaciones de riesgo de pérdida o dete-

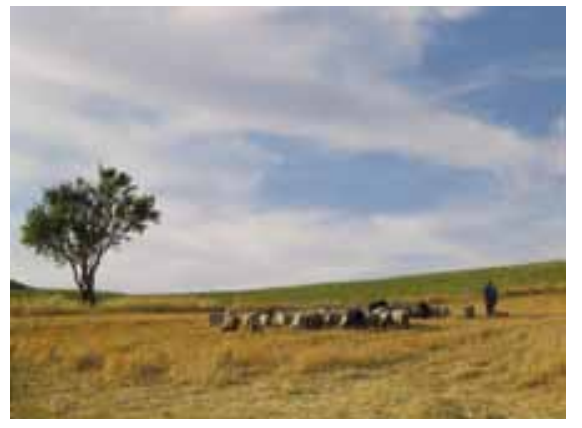

rioro del patrimonio cultural. Ello permitirá protocolizar metodologías y pautas comunes para la conservación y difusión de los recursos culturales de la comarca, adoptando líneas de investigación más coherentes y encaminadas al conocimiento histórico, a la conservación y a la puesta en valor del patrimonio de la Comarca de los Montes Orientales. Se trata, en suma, de diagnosticar las actuaciones que incidan o pueden incidir en un futuro próximo sobre su conservación; el de establecer las directrices sobre el tratamiento preventivo de dichos patrimonios dentro de todos los procesos de transformación territoriales y urbanísticos; o, el de proponer distintas actuaciones que permitan proteger, conservar, investigar y poner este patrimonio a disposición de la ciudadanía.

La Carta Patrimonial se convierte asi en un instrumento de estudio global del patrimonio cultural, que asume las líneas emprendidas ya por la Consejería en la elaboración de las Cartas Arqueológicas; y que suma también por primera vez en nuestra Comunidad la primera Carta Etnológica en redacción en el municipio onubense de Almonaster la Real.

Con la finalidad de dar difusión a estas Cartas del Patrimonio Cultural de Andalucía, la Dirección General de Bienes Culturales ha iniciado una campaña de divulgación, con la edición de 2.000 folletos informativos, entre los municipios, diputaciones provinciales, comarcas y universidades para dar a conocer los nuevos instrumentos de gestión y explicar las líneas de fomento a las que se pueden acoger para su redacción.

Finalmente, en estos momentos, la Consejería de Cultura se encuentra evaluando distintas solicitudes de subvención para la redacción indistinta de Cartas Patrimoniales, Arqueológicas y Etnológicas para la anualidad 2010.

\section{Arturo del Pino Ruiz}

Servicio de Investigación y Difusión del Patrimonio Histórico

Dirección General de Bienes Culturales 